\title{
PRÁTICA PEDAGÓGICA INCLUSIVA DE PROFESSORES QUE ENSINAM MATEMÁTICA NOS ANOS INICIAIS DO ENSINO FUNDAMENTAL
}

\author{
INCLUSIVE PEDAGOGICAL PRACTICE OF TEACHERS WHO \\ TEACH MATHEMATICS IN THE EARLY YEARS OF ELEMENTARY SCHOOL
}

REINALDO FEIO LIMA ${ }^{1}$

\section{RESUMO}

0 presente artigo objetiva identificar e compreender a prática pedagógica inclusiva de professores que ensinam matemática nos anos iniciais do Ensino Fundamental. 0 delineamento metodológico utilizado foi o levantamento bibliográfico dos textos completos, publicados em anais de reuniões científicas nacionais realizadas pela Associação Nacional de Pós-Graduação e Pesquisa em Educação (ANPED), no período 2006-2017. 0 corpus constituído reúne seis artigos. Para garantir a organização e rigor da análise, inspiramo-nos no método análise de conteúdo fundamentado em Bardin (2011; 2016). A análise de conteúdo revela elementos dos contextos da prática pedagógica inclusiva de professores que ensinam matemática nos anos iniciais do Ensino Fundamental: formação continuada, experiência da docência e desempenho ativo no seu processo de formação. Tais elementos se inter-relacionam e evidenciam distintos aportes teóricos e metodológicos que dão sustentação ao processo formativo.

Palavras-chave: Prática pedagógica inclusiva. Formação de professores que ensinam matemática. Anos iniciais. ANPED.

\section{ABSTRACT}

This article aims to identify and understand the inclusive pedagogical practice of teachers who teach mathematics in early years of elementary school. The methodological outline used was the bibliographic survey of the complete texts, published in annals of national scientific meetings held by the Associação Nacional de Pós-Graduação e Pesquisa em Educação (ANPED), in the period 2006-2017. The constituted corpus gathers six articles. To ensure the organization and rigor of the analysis, we were inspired by the content analysis method based on Bardin (2011; 2016). The content analysis reveals inclusive pedagogical practice contexts elements of teachers who teach mathematics in the early years of elementary school: continuing education, teaching experience and active performance in their training process. These elements are interrelated and show different theoretical contributions and methodological aspects that support the formative process.

Keywords: Inclusive pedagogical practice. Teacher training that teach mathematics. Initial years. ANPED.

\section{RESUMEN}

Este artículo tiene como objetivo identificar y comprender la práctica pedagógica inclusiva de los maestros que enseñan matemáticas en los primeros años de la escuela primaria. El esquema metodológico utilizado fue la encuesta bibliográfica de los textos completos, publicada en anales de reuniones científicas nacionales celebradas por la Associação Nacional de Pós-Graduação e Pesquisa em Educação (ANPED), en el período 2006-2017. El corpus constituido reúne seis artículos. Para garantizar la organización y el rigor del análisis, nos inspiramos en el método de análisis de contenido basado en Bardin (2011; 2016). El análisis de contenido revela elementos de contextos de la práctica 
pedagógica inclusiva de maestros que enseñan matemáticas en los primeros años de la escuela primaria: educación continua, experiencia docente y desempeño activo en su proceso de capacitación. Estos elementos están interrelacionados y muestran diferentes contribuciones teóricas. y aspectos metodológicos que apoyan el proceso formativo.

Palabras clave: Práctica pedagógica inclusiva. Formación de docentes que enseñan matemáticas. Años iniciales. ANPED.

\section{INTRODUÇÃO}

Nas últimas décadas temos presenciado a preocupação de pesquisadores com o mapeamento e a análise da produção científica, e consideramos pertinente essa preocupação, pois apresenta 0 crescimento e as especificidades em todas as áreas de conhecimento. Esse mapeamento permite aos pesquisadores a identificação e a sistematização dos temas já estudados, podendo apresentar os avanços e as lacunas na produção científica, fornecendo futuras implicações destes estudos para as novas produções científicas. Além disso, é possível analisar também os aspectos sobre '0 que' e 'o como' em sala de aula (BERNSTEIN, 1990), portanto sobre o professor e sobre as técnicas e métodos que podem tornar uma prática pedagógica inclusiva.

Dessa forma, o desenvolvimento da Prática Pedagógica (PP) e da Prática Pedagógica Inclusiva (PPI), a última por assumir alguns princípios da PP, como as relações entre professores e estudantes para ensinar e aprender determinado conteúdo matemático (BERNSTEIN, 2000), deve ajudar as crianças dos anos iniciais do Ensino Fundamental no desenvolvimento de meios que deem sentido à disciplina de matemática, já que as atividades organizadas pelos(as) professores(as) são condicionantes da prática pedagógica (BARBOSA, 2013), podendo limitar ou possibilitar a comunicação na relação pedagógica entre professor e estudantes (PRADO; SILVA; SANTANA, 2013).

Mendes (2006, p. 402), em trabalho que analisa o debate sobre inclusão escolar no Brasil, chama a atenção para a necessidade de trazer a prática pedagógica para o foco da pesquisa.

Entretanto, só 0 acesso não é suficiente, e traduzir a filosofia de inclusão das leis, dos planos e das intenções para a realidade dos sistemas e das escolas requer conhecimento e prática. É preciso, portanto, questionar: Qual a prática necessária? E o conhecimento necessário para fundamentar a prática? E este é, sem dúvida nenhuma, um exercício para a pesquisa científica.

É justamente nessa direção que este artigo pretende contribuir. Optamos por uma análise da produção científica na área da Educação Matemática, com foco para os aspectos da prática pedagógica inclusiva, de professores que ensinam matemática nos anos iniciais do Ensino Fundamental. No entanto, delimitamos nosso estudo para os textos publicados pelo Grupo de Trabalho (GT) 13 (Educação Fundamental) da Associação Nacional de Pós-Graduação e Pesquisa em Educação (ANPED), que ocorreram respectivamente nos anos de 2006 a 2017. 0 recorte temporal justifica-se pelo interesse em conhecer as produções científicas mais recentes no campo.

A escolha pelas Reuniões Científicas Anuais da ANPED, como o banco de dados para este artigo, justifica-se pela sua excelência, por ser considerada a mais qualificada associação na área de pós-graduação em educação do país, que socializa/divulga as pesquisas científicas sobre as diversas áreas da educação e seus temas da atualidade e por disponibilizar online suas produções acadêmicas (THESING; COSTAS, 2017). Isso indica a sua relevância e, possivelmente, a sua inesgotável discussão 
no que se refere às análises necessárias destes aspectos (INGLES et al., 2014). Outro aspecto a ser destacado neste artigo são as contribuições das práticas pedagógicas inclusivas no processo de ensino e de aprendizagem de estudantes com deficiências e outras condições atípicas de desenvolvimento (FONTES, 2007; BEYER, 2012).

A produção de pesquisas na área da Educação Matemática Inclusiva (EMI) é um meio de fazermos questionamentos e tentarmos respondê-los, comprometidos com 0 aumento da produção acadêmica em Educação Matemática. Em decorrência, algumas questões suscitam investigação neste momento: 0 que tem sido produzido na área científica em relação à EMI no GT13?

Dessa forma, o objetivo deste artigo é identificar e compreender a prática pedagógica inclusiva de professores que ensinam matemática nos anos iniciais do Ensino Fundamental, por meio de textos completos, publicados nas edições da Associação Nacional de Pós-Graduação e Pesquisa em Educação (ANPED), que ocorreram respectivamente nos anos de 2006 a 2017.

Como percurso metodológico, optamos pela pesquisa bibliográfica exploratória, de abordagem quali-quantitativa (MARCONl; LAKATOS, 2009) na qual objetivamos conhecer as pesquisas realizadas e de que forma foram desenvolvidas, a fim de que possamos registar, analisar e correlacionar fatos ou fenômenos (variáveis) sem manipulá-IOS (JARDILINO; ROSSI; SANTOS, 2000), já que buscamos compreender a prática pedagógica inclusiva a partir de referências teóricas publicadas em documentos, neste caso, os textos publicados no GT13.

Concomitantemente, utilizamos a técnica de pesquisa análise de conteúdo e priorizamos levantar as informações representadas nesses textos da produção científica nos anais da ANPED, por exemplo: área de estudo; definição do problema de pesquisa; aspectos metodológicos e teóricos utilizados; autores; ano e programa no qual a pesquisa foi desenvolvida; objetivos; espaços e participantes da pesquisa. 0 termo texto é empregado para designar representações pedagógicas, cuja função é remeter a uma determinada prática pedagógica inclusiva com o fim de comunicar alguma coisa, sendo que ele pode assumir diferentes formas, tais como: oral, escrita, gestual e outras (BERNSTEIN, 1990).

Este artigo tem a pretensão de se somar a outras pesquisas, contribuindo com a Ciência, Educação, Educação Matemática e a Educação Matemática Inclusiva, devendo ser visto como contributo teórico para professores e pesquisadores interessados na temática estudada. Buscamos, com isso, trazer pistas sobre "[...] o já construído e produzido para depois buscar o que ainda não foi feito [...]" (FERREIRA, 2002, p. 259).

\section{DO PERCURSO METODOLÓGICO}

0 percurso metodológico adotado no desenvolvimento desse estudo é de natureza qualitativa e exploratória, a qual está centrada em aspectos de "compreensão e explicação das relações sociais, preocupando-se com realidades que não podem ser quantificadas" (GERHARDT; SILVEIRA, 2009, p. 32).

Embora o levantamento dos dados que constituem o lócus esteja atrelado a dados quantitativos, seu estudo é de natureza interpretativa, portanto requer uma abordagem qualitativa, já que "enfatiza mais o processo do que o produto e se preocupa em retratar, interpretativamente, a perspectiva dos participantes" (SCHITTLER; MOREIRA, 2014, p. 265).

Para tanto, este artigo exploratório objetiva "[...] proporcionar maior familiaridade com o problema" (GIL, 2002, p. 41), assim definido: Como as produções científicas têm estudado a Educação Matemática Inclusiva nos anos iniciais do Ensino Fundamental? Para responder a essa questão, utilizamos a pesquisa bibliográfica descritiva, desenvolvida em base de material já elaborado, como 
os textos, com análise quali-quantitativa, a partir das produções selecionadas em bases de dados científicos. Para isso, utilizamos os bancos de dados da ANPED, no intuito de levantar os textos que constituíram o lócus de investigação no período de 2006 a 2017, e também os seguintes descritores: educação especial; educação inclusiva; prática pedagógica; ensino de matemática; ensino fundamental.

0 material encontrado foi colocado em planilhas do Microsoft Excel, segundo o banco de dados pesquisado e os descritores. Nessa planilha, contemplamos as seguintes informações: nome do texto; ano de publicação; programa e local; e autores.

No Quadro 1, a seguir, apresentamos uma síntese do método utilizado, em que destacamos os critérios de seleção dos estudos:

Quadro 1 - Síntese do método utilizado para seleção dos textos.

\begin{tabular}{|c|l|}
\hline CRITÉRIO & \multicolumn{1}{c|}{ SELEÇÃO } \\
\hline Pergunta norteadora & 0 que tem sido produzido na área científica em relação à EMI no GT13? \\
\hline Fonte de busca & $\begin{array}{l}\text { Anais do Grupo de Trabalho GT13 (Educação Fundamental) da Associação Nacional de } \\
\text { Pós-Graduação e Pesquisa em Educação (ANPED). }\end{array}$ \\
\hline Período & Últimas dez edições do evento. \\
\hline Termos de busca & $\begin{array}{l}\text { "educação especial", "educação inclusiva", "prática pedagógica", "ensino de matemática" } \\
\text { e "ensino fundamental". }\end{array}$ \\
\hline Critério de inclusão & $\begin{array}{l}\text { Textos publicados nos anais da ANPED, entre os anos de 2006 a 2019, e relacionados } \\
\text { a estudos empíricos nos anos iniciais do Ensino Fundamental. }\end{array}$ \\
\hline Critério de exclusão & $\begin{array}{l}\text { Artigos com metodologia de revisão de literatura, ou que não contemplem investigação } \\
\text { na prática pedagógica de professores que ensinam matemática nos anos iniciais do } \\
\text { Ensino Fundamental. }\end{array}$ \\
\hline
\end{tabular}

Fonte: Construção do autor com base na pesquisa de Melo e Pessoa (2018).

Em nossa busca encontramos seis artigos científicos nos anais da ANPED, nas dez edições analisadas, de um total de 179. A Tabela 1, abaixo, apresenta informações quantitativas dos textos encontrados nas edições da ANPED, as quais se enquadram em nossos critérios estabelecidos (Quadro 1).

Tabela 1 - Quantidade e distribuição de textos.

\begin{tabular}{|c|c|c|c|}
\hline Edição & Ano de publicação & Textos publicados & Textos selecionados \\
\hline 29 & 2006 & 12 & 0 \\
\hline 30 & 2007 & 16 & 1 \\
\hline 31 & 2008 & 18 & 1 \\
\hline 32 & 2009 & 21 & 1 \\
\hline 33 & 2010 & 22 & 1 \\
\hline 34 & 2011 & 16 & 0 \\
\hline 35 & 2012 & 19 & 0 \\
\hline 36 & 2013 & 17 & 0 \\
\hline 37 & 2015 & 22 & 1 \\
\hline 38 & 2017 & 16 & 1 \\
\hline
\end{tabular}

Fonte: Construção do autor. 
Os artigos selecionados foram publicados entre 2006 e 2017. Sendo que os artigos selecionados para a análise de dados foram publicados entre 2007 e 2017. Assim, registramos um artigo em 2007, um em 2008, um em 2009, um em 2010, um em 2015 e um em 2017. Isso nos levou a inferir que o primeiro aspecto observado neste mapeamento foi o pequeno número de publicações que abordaram a temática em questão. Tal resultado apontou baixa publicação com foco na prática pedagógica inclusiva, o que reflete uma preocupação em discutir a inserção da prática pedagógica inclusiva no ensino de Matemática: "uma prática que demande, necessariamente, reflexão (uma práxis, como se tem afirmado), [...] uma reflexão que, sugerida pela prática, visa a uma efetiva intervenção na ação pedagógica" (GARNICA, 1999, p. 60-61).

Das seis pesquisas mapeadas, quatro (T03, T04, T05 e T06) foram produzidas em instituições particulares e duas em instituições públicas estaduais ou federais (T01 e T02). Dentre essas, há aquelas pesquisas desenvolvidas em parceria com outras Instituições de Ensino Superior (IES), por exemplo, T02 - Universidade Federal do Estado do Rio de Janeiro (UNIRIO) e o Instituto Superior de Educação do Rio de Janeiro (ISERJ); T04 - Universidade Federal de Pelotas (UFPEL), Universidade Federal do Pampa (UNIPAMPA), Universidade Federal do Espírito Santo (UFES) e Universidade Federal do Pampa (UNIPAMPA). Vale destacar que essas produções de conhecimento científico estão sendo desenvolvidas nessas instituições e contam com o apoio da Coordenação de Aperfeiçoamento de Pessoal de Nível Superior (CAPES) ou do Conselho Nacional de Desenvolvimento Científico e Tecnológico (CNPQ).

A seguir apresentamos um quadro contendo os dados dos textos selecionados: código, ano, instituição, autor e título, conforme descrição no Quadro 2, em ordem cronológica, o período de 2006 a 2017:

Quadro 2 - Síntese dos dados dos textos selecionados

\begin{tabular}{|c|c|c|l|l|}
\hline CÓDIGO & ANO & INSTITUIÇÃO & \multicolumn{1}{|c|}{ AUTOR } & \multicolumn{1}{|c|}{ TítULO } \\
\hline T01 & 2007 & UNIRIO & Carmen Sanches Sampaio & $\begin{array}{l}\text { A complexidade do processo ensino/aprendizagem e a } \\
\text { possibilidade de uma prática pedagógica inclusiva na } \\
\text { escola de ensino fundamental. }\end{array}$ \\
\hline T02 & 2008 & $\begin{array}{l}\text { UNIRIO } \\
\text { ISERJ }\end{array}$ & $\begin{array}{l}\text { Carmen Sanches Sampaio } \\
\text { Margarida dos Santos Costa }\end{array}$ & $\begin{array}{l}\text { Na articulação prática/teoria/prática a construção } \\
\text { cotidiana de ações pedagógicas inclusivas. }\end{array}$ \\
\hline T03 & 2009 & UNIPAC & Marília Pimentel & Prática pedagógica e diversidade. \\
\hline T04 & 2010 & $\begin{array}{l}\text { UFPEL } \\
\text { UNIPAMPA }\end{array}$ & $\begin{array}{l}\text { Mauro Augusto Burkert Del Pino } \\
\text { Gilceane Caetano Porto }\end{array}$ & $\begin{array}{l}\text { A exclusão escolar na rede pública municipal de ensi- } \\
\text { no: a história continua no século XXI. }\end{array}$ \\
\hline T05 & 2015 & $\begin{array}{l}\text { UFES } \\
\text { UNISINOS }\end{array}$ & $\begin{array}{l}\text { Lucyenne Matos da Costa Vieira- } \\
\text {-Machado } \\
\text { Maura Corcini Lopes }\end{array}$ & $\begin{array}{l}\text { Experiências docentes: é possível viver com o outro } \\
\text { desde fora da inclusão. }\end{array}$ \\
\hline T06 & 2017 & UNISINOS & $\begin{array}{l}\text { Deise Andreia Enzweiler } \\
\text { Raquel Fröhlich }\end{array}$ & $\begin{array}{l}\text { Discursos sobre inclusão escolar no ciclo de alfa- } \\
\text { betização: uma análise sobre o pacto nacional pela } \\
\text { alfabetização na idade certa (PNAIC). }\end{array}$ \\
\hline
\end{tabular}

Fonte: Construção do autor.

Após a identificação dos textos, realizamos uma leitura completa com o objetivo de aprofundar 0 entendimento dos objetivos propostos e de aspectos teórico-metodológicos dos mesmos. Para isso, este artigo se caracteriza como bibliográfica, um "Estado do Conhecimento", pois segundo Romanowski e Ens (2006, p. 39) "[...] 0 estudo que aborda apenas um setor das publicações sobre 0 tema estudado vem sendo denominado de estado do conhecimento". Para Morosini e Fernandes (2014, p. 155) é um processo de "identificação, registro e categorização que levam à reflexão e síntese de uma 
determinada área, em um determinado espaço de tempo", que visa propiciar, aos pesquisadores, um contato com 0 que já foi produzido anteriormente sobre 0 objeto pesquisado (e síntese 0 artigo apresentado tem, já que apresenta, ao final, categorias a priori nas quais foram agrupados os trabalhos lidos). Sobre este tipo de pesquisa assim se manifesta Ferreira (2002, p. 257):

Definidas como de caráter bibliográfico, elas parecem trazer em comum o desafio de mapear e discutir uma certa produção acadêmica em diferentes campos do conhecimento, tentando responder aspectos e dimensões que vêm sendo destacados e privilegiados em diferentes épocas e lugares, de que formas e em que condições têm sido produzidas certas dissertações de mestrado, teses de doutorado, publicações em periódicos e comunicações em anais de congressos e seminários.

Desse modo, ela "[...] não é mera repetição do que já foi dito ou escrito sobre 0 assunto, mas propicia o exame de um tema sob novo enfoque ou abordagem, chegando a conclusões inovadoras" (LAKATOS; MARCONI, 1999, p. 73, grifo nosso). Dessa forma, reunimos informações quantitativas e qualitativas neste artigo, a fim de tornar compreensíveis os dados produzidos. Á vista disso, este estudo apresenta dados mensurados numericamente e qualitativamente, na busca por proporcionar melhor compreensão do fenômeno observado (CRESWELL, 2007).

À luz das concepções de Morosini e Fernandes (2014), Romanowski e Ens (2006), Ferreira (2002) e Lakatos e Marconi (1999), realizamos a leitura e análise minuciosas dos textos com aspectos relacionados ao nosso objetivo, sistematizamos em categorias a priori que seguiram os termos ou expressões dos descritores de busca. Em seguida, investigamos as implicações dos estudos para as práticas pedagógicas inclusivas e, principalmente, para as novas contribuições científicas. Na seção seguinte, apresentamos os resultados dessa análise detalhada dos seis artigos selecionados.

\section{APRESENTAÇÃO E DISCUSSÃO DOS DADOS}

Nesta seção, são apresentados e discutidos os trabalhos que fizeram parte do corpus textual. Em cada um deles, o leitor encontrará um breve resumo do objetivo, da metodologia e dos principais resultados apontados pelo(a) autor(a) da pesquisa.

A investigação do texto T01 (SAMPAI0, 2007), de modo geral, consistiu em apresentar um recorte de sua tese de doutorado, em que deu continuidade e intensificou um processo de formação continuada de um grupo de professoras alfabetizadoras de uma escola pública, vinculada à Secretaria de Ciência e Tecnologia do Estado do Rio de Janeiro que, insatisfeitas com o já sabido (CORAZZA, 1996), há mais de uma década, refletem sobre suas práticas pedagógicas, investigando o processo de construção vivido pelos alunos e alunas e por elas mesmas.

Para capturar as especificidades dessa formação, um grupo de professoras alfabetizadoras, incomodadas com essa situação, aceitou 0 desafio de procurar compreender 0 entendimento dos seus alunos e alunas. Em suma, as análises revelaram que o processo de formação permitiu às participantes da pesquisa, professoras e pesquisadoras, perceber e considerar que as idiossincrasias da aprendizagem das crianças não são nada fáceis. Isso nos leva a compreender o processo de ensino e de aprendizagem de maneira bem diferente do modo ensinado e aprendido. A autora concluiu que a prática alfabetizadora implementada, no cotidiano dessa escola pública, afirma a leitura e a escrita como prática dialógica, discursiva, significativa (SMOLKA, 1988). 
No texto T02, Sampaio e Costa (2005) socializaram e colocaram em discussão ações pedagógicas comprometidas com a inclusão de alunos e alunas, fruto de práticas investigativas realizadas durante o Mestrado e Doutorado das autoras. Para isso, um grupo de professoras no movimento de discutir, coletivamente, sobre as práticas pedagógicas realizadas cotidianamente na escola começaram a tomar o processo de ensino e de aprendizagem como objeto de reflexão e análise, utilizando o paradigma indiciário de cunho qualitativo proposto por GINZBURG (1989) para abandonar formas preestabelecidas e "legitimadas" de ler o "real". A leitura de indícios possibilitou que a ação investigativa duvidasse e interrogasse 0 que se apresentava como evidente. Os resultados mostraram que investigar práticas pedagógicas realizadas por sujeitos encarnados, atores e autores da ação pedagógica desenvolvida e de suas próprias vidas colocou-nos diante do desafio de mergulhar (ALVES, 2001) no cotidiano escolar, tentando compreender suas complexidades e articulações.

No texto T03, de Pimentel (2009), a proposta de investigação visava promover atividades reflexivas com os professores como forma de intervenção no sistema pesquisado (THIOLLENT, 1994). Objetivou, com esses momentos, esclarecer sobre a natureza de situações problemáticas e tomada de consciência da diversidade dos grupos envolvidos. Os procedimentos metodológicos utilizados para obtenção dos dados constaram de entrevistas semiestruturadas, com itens abertos, registros de depoimentos escritos e orais sobre atividades de sala de aula e reuniões do grupo. As atividades dos grupos foram registradas sob a forma de relatórios, gravação, fotos, etc. Os resultados apontaram que os professores evidenciaram uma relação afetiva acentuada com a carreira, atribuindo-lhe expressões de "prazer", "vício", "desejo" e "atração" e revelando uma trajetória de amadurecimento de experiências, por vezes, diversificadas em outras funções pedagógicas.

No texto T04, Del Pino e Porto (2010), em linhas gerais, apresentaram resultados preliminares da pesquisa em andamento "0 lugar do professor na exclusão escolar", que visava investigar a expressão do fenômeno da exclusão escolar na rede de ensino público municipal da cidade de Pelotas, estado do Rio Grande do Sul. Metodologicamente, pautou-se em pesquisa com característica de um estudo de caráter exploratório, descritivo e qualitativo (BOGDAN; BIKLEN, 1994). Exploratório porque permite ao investigador aumentar sua experiência e conhecimento em torno de determinado problema (TRIVIÑOS, 1987). Os resultados indicaram que a realidade da exclusão escolar não pode ser abarcada e compreendida apenas com dados quantitativos. É certo que não é possível diminuir a importância dos indicadores aqui obtidos e produzidos. A compreensão e o entendimento do fenômeno da exclusão escolar, em toda sua complexidade, necessitam de aporte teórico e, sem dúvida, de conhecimentos ancorados na dura realidade encontrada ainda hoje na escola pública brasileira.

No texto T05, Vieira-Machado e Lopes (2015) propuseram um trabalho em que discutiram as práticas de subjetivação, que constituem as verdades sobre a inclusão escolar nos docentes atuantes na escola básica. Para tanto, 42 narrativas de docentes de 10 capitais brasileiras foram produzidas, ora em grupos de até oito docentes, seguindo uma metodologia de roda de conversa, e ora individualmente. As narrativas produzidas priorizaram o tema da relação com 0 outro/discente nas experiências escolares. Assim, operando nas análises das narrativas com o conceito-ferramenta inclusão, matriz de experiência e práticas de subjetivação, este trabalho parte de uma teorização de inspiração foucaultiana para defender a tese de que é possível viver com o outro desde fora da inclusão com base nas experiências docentes. Por fim, os resultados evidenciaram a compreensão pelos diálogos com os professores. À medida que mudam-se a linguagem, o modo de ver e nomear as relações com este outro, a necessidade da palavra inclusão passa a ser redundante, pois requer relação responsiva e responsável de cuidado consigo e com este outro. 
No texto T06, Enzweiler e Fröhlich (2017), de modo geral, descreveram e problematizaram os discursos sobre inclusão escolar mapeados nos materiais que orientam a formação dos professores no Pacto Nacional pela Alfabetização na Idade Certa (PNAIC). Para tanto, as autoras utilizaram a ferramenta conceitual do discurso, a partir do campo dos estudos foucaultianos. Após análise, os resultados permitiram pontuar que os discursos sobre inclusão escolar do PNAIC, focados nos sujeitos deficientes e nos sujeitos não aprendentes, sugerem uma individualização dos processos de aprendizagem partindo de uma diversificação no planejamento docente. Por fim, identificaram um paradoxo nas relações da inclusão escolar com o ciclo de alfabetização, pois o PNAIC, ao mesmo tempo em que se alinha e festeja uma perspectiva inclusiva, combate os sujeitos da inclusão para os quais direciona as suas intervenções (deficientes e não aprendentes).

Após apresentarmos o que dizem os materiais empíricos dos seis textos acima, passamos, na sequência, à explicitação das compreensões, da reflexão que dela emergiu por meio do movimento de análise de conteúdo.

Do ponto de vista dos elementos dos contextos, da prática pedagógica inclusiva de professores que ensinam matemática nos anos iniciais do Ensino Fundamental, sinalizamos a formação continuada como o primeiro elemento da prática pedagógica inclusiva, que, segundo os autores dos textos, essa formação ampliou os significados que foram atribuídos às questões relacionadas aos seus conhecimentos profissionais. Em ambos os textos repousa a preocupação dos autores na reflexão sobre a ação, na ação e para a ação (PÉREZ GÓMEZ, 1995). É exemplo desse primeiro elemento o excerto abaixo:

A experiência de formação vivenciada e investigada, nesta escola, investe na formação da professora como pesquisadora da sua própria prática, professora-pesquisadora (GARCIA \& ALVES, 2002), que, mediante a reflexão compartilhada na ação e sobre a ação (PÉREZ GÓMEZ, 1995), vai assumindo uma prática pedagógica que rompe com a dicotomia entre o pensar e o fazer (TEXT0 02, 2008, p. 2).

De acordo com esse trecho, podemos inferir um segundo elemento da prática pedagógica inclusiva, a experiência da docência que acontece no momento em que participam da formação (com) partilhada em pequenos grupos, formados por professores experientes e futuros professores com diferentes histórias de vida, permitindo partilhar experiências da docência, ou seja, o compartilhamento de diferentes experiências de sala de aula, podem negociar e produzir significados que possibilitam mudanças em sua prática pedagógica inclusiva (BALDINI; CYRINO, 2016). Esse segundo elemento se coaduna com as ideias visualizadas no extrato que se segue:

Tardif (2000) adverte para os saberes que são mobilizados pelo professor em sua prática, e que são formulados nos primeiros anos de sua prática pedagógica as quais denomina "saber experiencial" e a partir daí se desenvolvem no âmbito de uma "carreira", contendo dimensões identitárias e de socialização profissional. Alerta para a ausência de uma teoria unitária que oriente a prática do professor. Segundo Tardif, o professor lança mão de várias concepções e técnicas provenientes de fontes diversas, como: "sua história de vida, familiar, cultura escolar, conhecimentos disciplinares, didáticos" (TEXT0 03, 2008, p. 9).

Logo, o(a) professor(a) não incorpora simplesmente os elementos que lhe são passados, mas revela sua capacidade de criar currículo para além dessas práticas no cotidiano escolar. Isso permite 
aos participantes da formação continuada saber experiencial com foco nas referências do cotidiano, da sua história de vida, familiar, cultura escolar, conhecimentos disciplinares que são mobilizados/ constituídos no decorrer dos encontros da formação continuada, assumindo, com suas ações, uma participação no grupo (BALDINI; CYRINO, 2016).

0 resultado desses dois elementos acirrou o debate entre professores, educadores e pesquisadores no sentido de promover um sujeito constituído pelo outro e constituído por si-sujeito em objeto de construção para si mesmo (CARVALHO, 2014). Assim, quando o(a) professor(a) torna-se o objeto de sua própria observação, observa as suas práticas pedagógicas, julga-as, analisa-as dentro das possibilidades históricas vividas, ele se torna objeto de transformação de si mesmo e não apenas conduzido pelo processo histórico imanente da inclusão escolar (T05). Portanto, a partir desses debates entre os agentes da formação continuada, desemboca um terceiro elemento da prática pedagógica inclusiva - desempenho ativo no processo de formação - que são ações de sua própria prática pedagógica inclusiva; são profissionais que possuem conhecimentos sobre sua ação, que refletem sobre ela como uma prática social e são capazes de produzir novos conhecimentos (T01). Tiveram liberdade para opinar, discutir, concordar, discordar, expor suas ideias, negociar significados em um processo dinâmico que favoreceu aos participantes se tornarem agentes de sua aprendizagem, proporcionando a constituição de conhecimentos profissionais relativos ao conteúdo, à organização e à condução de uma aula usando a tecnologia digital. Desse modo, desempenharam um papel ativo no seu processo de formação (BALDINI; CYRINO, 2016).

Do ponto de vista dos aportes teóricos, que são assumidos nos seis textos sobre a prática pedagógica inclusiva de professores que ensinam matemática nos anos iniciais do Ensino Fundamental, identificamos que somente os textos T02, T05 e T06 sinalizam o referencial teórico.

0 texto T02 apresenta uma investigação feita com um grupo de professoras no movimento de discutir, coletivamente, sobre as práticas pedagógicas realizadas cotidianamente na escola, em turmas especiais, com base na teoria de Vygotsky. Essa teoria permite a preocupação com a ação pedagógica e o papel do professor e do aluno no processo de ensino e de aprendizagem, "leva-nos a considerar a ajuda e o fazer em cooperação como constitutivos do movimento de construção de conhecimentos" (TEXTO 02, 2008, p. 7), como pode ser visto nos exemplos abaixo:

Tendo como referência o conceito de Zona de Desenvolvimento Proximal (VYGOTSKY, 1989), as orientadoras pedagógicas convidavam e instigavam as professoras a investir no conhecimento prospectivo da criança, na tentativa de romper com a oposição saber/não saber que considera apenas 0 desenvolvimento consolidado (TEXTO 02, 2008, p. 4).

No que diz respeito à aprendizagem, ele propôs o conceito de Zona de Desenvolvimento Proximal, 0 qual tem sido de grande relevância nas pesquisas acerca das estratégias didáticas de ensino em várias áreas do conhecimento humano. Nesse sentido, Vygotsky (2007) afirma que os indivíduos com necessidades especiais têm um potencial de desenvolvimento cognitivo normal, alcançado pelas interações e intervenções do professor por meio de estímulos e instrumentos, ou seja, toda criança tem capacidade de aprender e 0 que irá proporcionará esse aprendizado é a mediação (PINHEIR0 et al., 2020).

No texto T05, Vieira-Machado e Lopes (2005) utilizaram os conceitos-ferramenta inclusão, matriz de experiência e práticas de subjetivação de inspiração foucaultiana para analisar 42 narrativas de docentes de 10 capitais brasileiras, seguindo ora uma metodologia de roda de conversa e ora individualmente, a 
exemplo, "operando nas análises das narrativas com os conceitos-ferramenta inclusão, matriz de experiência e práticas de subjetivação este trabalho parte de uma teorização de inspiração foucaultiana" (TEXT0 05, 2015, p. 1). Já 0 texto T06 utilizou a mesma inspiração foucaultiana para problematizar os discursos sobre inclusão escolar, mapeados nos materiais que orientam a formação dos professores no Pacto Nacional pela Alfabetização na Idade Certa (PNAIC). Essa inspiração pode ser visualizada no extrato que se segue: "justificamos os usos metodológicos e conceituais utilizados, marcados pelo campo dos estudos foucaultianos e pelo uso conceitual do discurso" (TEXTO 06, 2017, p. 2).

Nos demais textos (T01, T03 e T04), apesar de não assumirem um aporte teórico ao longo da pesquisa, encontramos um total de 71 referências distintas relacionadas à temática. Mediante esse grande número, exemplificamos os autores dos estudos do corpus e da análise da prática pedagógica inclusiva em cada contexto investigado. Eles foram considerados estruturais e fundantes para sustentar a discussão teórica e metodológica (MOREIRA; MACEDO, 2002; TARDIF, 2000; CANDAU, 1998; SMOLKA, 1998; SCHÖN, 1995; PÉREZ GOMEZ, 1995; MORIN, 1995; CERTEAU, 1994).

Em suma, nesta análise dos aportes teóricos, verificamos que os embasamentos teóricos dos seis textos tiveram como bases teóricas autores diferentes. No entanto, os textos T05 e T06 seguiram uma mesma linha de pensamento, trabalhando com autores que visavam à melhor maneira de aprendizado utilizando-se da Teoria de Foucault. Em T02, os autores assumiram o conceito de Zona de Desenvolvimento Proximal da teoria de Vygotsky (1989; 1991), sendo que em T01, T03 e em T04 os autores não adotaram uma teoria como base para suas pesquisas.

Além disso, todos os artigos analisados procuraram, por meio da formação continuada, melhorias para a prática pedagógica inclusiva de professores que ensinam Matemática nos anos iniciais do Ensino Fundamental, buscando maneiras para que acontecesse o processo de ensino e de aprendizagem como objeto de reflexão e análise e, nesse processo, ocorresse uma interação com aprendizado, excluindo totalmente 0 isolamento desses estudantes, assim como se pode observar na pesquisa de Peixoto (2015).

Do ponto de vista dos aportes metodológicos que são assumidos nos seis textos, sobre a prática pedagógica inclusiva de professores que ensinam matemática nos anos iniciais do Ensino Fundamental, observamos que $12 \%$ dos textos apresentam uma seção ou parágrafo que exemplificam o delineamento metodológico, como descritos no extrato abaixo:

Os procedimentos metodológicos utilizados para obtenção dos dados constaram de entrevistas semiestruturadas, com itens abertos, registros de depoimentos escritos e orais sobre atividades de sala de aula e reuniões do grupo. As atividades dos grupos foram registradas sob a forma de relatórios, gravação, fotos, etc. Coube aos alunos executarem e avaliarem pequenos projetos de intervenção nas atividades práticas de sala de aula, a partir dos relatórios de observação produzidos (TEXTO 03, 2009, p. 10).

A pesquisa caracteriza-se por ser um estudo de caráter exploratório, descritivo e qualitativo. As professoras que irão compor a amostra serão alfabetizadoras que tenham em sua classe alunos que estejam repetindo a $1^{a}$ série. Os alunos que irão compor a amostra serão alunos multirrepetentes. Além da aplicação de entrevistas semiestruturadas às professoras e aos alunos, em cada etapa será feita uma descrição analítica de cada uma das quatro escolas. Para tanto, serão construídos instrumentos de investigação para realizar as análises necessárias para atingir os objetivos definidos pela pesquisa (TEXTO 04, 2020, p. 8). 
Interessa ouvir dos docentes quem eles denominam ou para quem eles se voltam ao recordar suas experiências escolares como docentes, bem como que rituais eles pontuam em suas práticas docentes. Para tanto, 42 narrativas de docentes de 10 capitais brasileiras foram produzidas, ora em grupos de até oito docentes, seguindo uma metodologia de roda de conversa, e ora individualmente (TEXTO 05, 2015, p. 2).

Para a análise de tais materiais, inspiramo-nos nas contribuições teóricas e metodológicas do campo dos estudos foucaultianos, principalmente no que se refere à ferramenta conceitual do discurso (TEXTO 06, 2017, p. 7).

Os textos analisados trouxeram uma abordagem de investigação qualitativa e quali-quantitava (T04). 0 foco geral tratou de formação continuada na perspectiva inclusiva, para que fosse possível buscar melhorias de interação e comunicação que proporcionassem eficácia na prática pedagógica. E ambos empregaram uma variedade de instrumentos de produção de dados, por exemplo, entrevistas, relatórios, gravação, fotos, narrativas.

De modo geral, nos textos analisados (T01, T02, T03, T04 e T05), os pesquisadores se fizeram presentes no contexto da pesquisa. Somente 0 T06 realizou uma análise documental nos materiais que orientam a formação dos professores no Pacto Nacional pela Alfabetização na Idade Certa (PNAIC). Todos os trabalhos também foram realizados com embasamento na revisão da literatura (teses e dissertações) que tratam da formação de professores que ensinam matemática nos anos iniciais do Ensino Fundamental.

É o momento de elaboração da síntese interpretativa, através de uma redação que possa relacionar temática com o objetivo e a questão da pesquisa.

\section{CONCLUSÕES E IMPLICAÇÕES}

0 objetivo principal deste estudo foi identificar e compreender a prática pedagógica inclusiva de professores que ensinam matemática nos anos iniciais do Ensino Fundamental, manifestada em textos publicados nas edições da Associação Nacional de Pós-Graduação e Pesquisa em Educação (ANPED), que ocorreram respectivamente nos anos de 2006 a 2017. Empreendidas as buscas nesses periódicos, para extrair artigos acadêmicos que tivessem, dentre suas palavras-chave, os descritores "educação especial", "educação inclusiva", "prática pedagógica", "ensino de matemática" e "ensino fundamental", obtivemos como resultado um corpus de pesquisa contendo 06 textos.

Esse quantitativo responde parcialmente à nossa questão de pesquisa: 0 que tem sido produzido na área científica em relação à EMI no GT13? Parafraseando os dados representados na Tabela 1, inferimos que há poucas produções com foco na prática pedagógica inclusiva de professores que ensinam matemática nos anos iniciais do Ensino Fundamental. Contudo, ainda que seja um número reduzido das pesquisas acadêmicas acerca da Educação Matemática Inclusiva no GT13, destacamos a emergência de mais discussões sobre essa temática, de modo a dar conta de todos os ordenamentos legais e práticas pedagógicas inclusivas desenvolvidas cotidianamente nas escolas.

A Figura 1 sintetiza as características da prática pedagógica inclusiva que são evidenciadas pelos textos dos materiais analisados. 
Figura 1 - Características da prática pedagógica inclusiva.

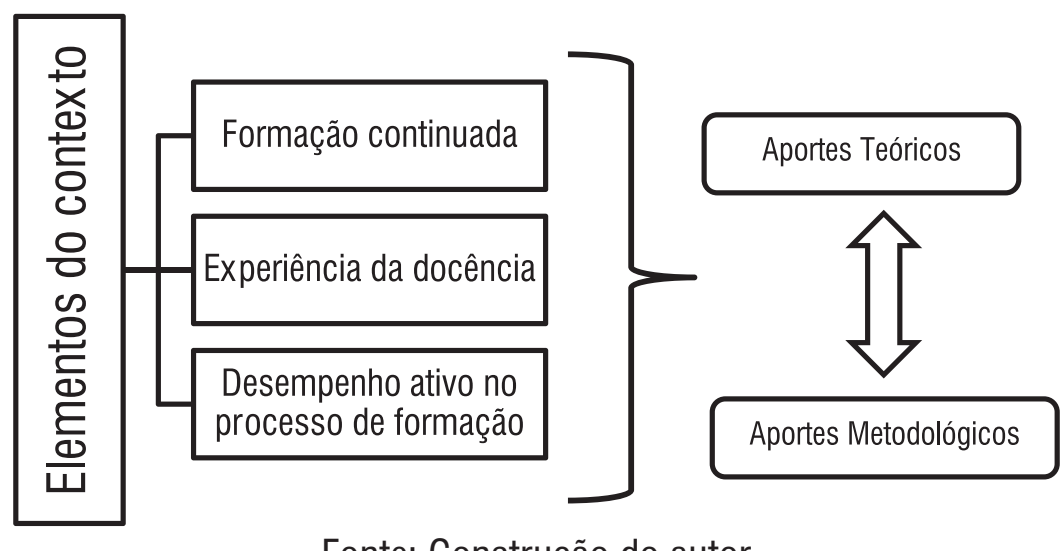

Fonte: Construção do autor.

As características apresentadas acima sinalizam nossa compreensão sobre a prática pedagógica inclusiva de professores que ensinam matemática nos anos iniciais do Ensino Fundamental, representadas em textos publicados no GT13 da ANPED.

Quando intitulamos elementos dos contextos discutidos neste artigo, como relacionados aos aspectos formativos que constituem as práticas pedagógicas inclusivas de professores que ensinam matemática nos anos iniciais do Ensino Fundamental, reconhecemos como estão aí representados, mesmo que implicitamente, o caráter contínuo e processual, a formação continuada, inclusive, pelo próprio sentido literal da expressão continuada que indica dar continuidade, verbo que imprime a ideia de movimento.

A nosso ver, como elemento central do estudo, e que perpassa por toda nossa análise compreensiva e a constituição das práticas pedagógicas inclusivas representadas em cada texto analisado, abarca, concomitantemente, traços das experiências da docência desses professores que atuam nos anos inicias do Ensino Fundamental, enquanto fonte de aprendizagem em complementaridade à formação inicial, e como mostraram as interpretações deste artigo, do desempenho ativo no processo de formação, enquanto contexto de experimentação de estratégias de ação pedagógica, que estão associadas ao seu compromisso ao exercício da docência e dar busca por estratégias de transformação de suas práticas.

Essas considerações desnudam distintos aportes teóricos e metodológicos que dão sustentação ao processo formativo, isto é, distintos modos de produzir conhecimentos para a formação de professores em Educação Matemática Inclusiva. Indicam, ainda, que a produção acadêmica sobre formação de professores que ensinam Matemática nos anos iniciais do Ensino Fundamental está sujeita à introdução de diferentes teorias e metodologias para a formação na perspectiva inclusiva. Revelam, ademais, a existência de uma orientação pragmática na/para formação continuada e de um paralelismo entre formação/sujeito/prática.

Em síntese, a prática pedagógica inclusiva de professores que ensinam Matemática nos anos iniciais do Ensino Fundamental, representadas nos textos do GT13 da ANPED, não se limita à utilização de estratégia de formação exclusivamente teórica, mas uma prática pedagógica inclusiva que se orienta por elas e para elas, buscando entrelaçar, a partir de suas vivências, indicativos das estratégias didáticas/pedagógicas que possam contribuir efetivamente com a Educação Matemática 
Inclusiva, sem que haja determinação. Essa prática deve acontecer de forma espontânea, livre de obrigações para que o professor possa se sentir confortável e acolhido durante as reflexões, os diálogos, as experiências, diferentes visões epistemológicas sobre 0 tema e as discussões sobre as dificuldades encontradas na prática pedagógica; e, além disso, para que ele se sinta confortável junto aos membros do grupo ou na roda de conversa, de tal modo que o professor, a partir de sua necessidade percebida na sala de aula, sinta-se impelido a fazer dela uma prática contínua e uma possível mudança da sua prática pedagógica em sala de aula.

Dito de outro modo, defendemos a necessidade de que as pesquisas com foco na Educação Matemática Inclusiva sejam inseridas no processo da formação de professores que ensinam Matemática nos anos iniciais do Ensino Fundamental, a fim de possibilitar que formandos e formadores reflitam sobre a formação em EMI, levando em consideração suas especificidades, para que possam programá-las e desenvolvê-las em sala de aula inclusiva de modo mais efetivo e prático. Isso porque entendemos que a pesquisa em EMI é, como o fazer pedagógico, um ato político (FREIRE, 1991). Esse fato nos conduz também a outro estudo futuro, em que se problematizem características teóricas, metodológicas e epistemológicas relevantes às investigações futuras, interessadas em discutir as especificidades da prática pedagógica inclusiva dos professores que ensinam Matemática nos anos iniciais do Ensino Fundamental.

Finalizamos este artigo convencidos de que investigar a Educação Matemática Inclusiva se firma como um campo emergente na Educação Matemática, em que implicações futuras ficam em aberto, o que propicia aos futuros pesquisadores, interessados em explorá-la, avançar em problemáticas relevantes para a formação continuada ou inicial de professores que ensinam Matemática nos anos iniciais do Ensino Fundamental. A pesquisa nesse campo emergencial precisa de um esforço coletivo nos próximos anos.

\section{REFERÊNCIAS}

ALVES, N. Decifrando o pergaminho - 0 cotidiano das escolas nas lógicas das redes cotidianas. In: OLIVEIRA, Inês B.; ALVES, Nilda (Org.). Pesquisa no/do cotidiano das escolas sobre redes de saberes. Rio de Janeiro: DP\&A, 2001, p. 1-8.

BALDINI, L.A.F.; CYRINO, M.C.C.T. Elementos da prática de uma comunidade de prática de professores de matemática na utilização do software GeoGebra. Revista UNÓN, n. 45, 2016.

BARBOSA, J.C. Designing written tasks in the pedagogic recontextualizing field: proposing a theoretical model. In: INTERNATIONAL CONFERENCE ON MATHEMATICS EDUCATION AND SOCIETY, 7., 2013, Cape Town. Proceedings [...] Cape Town: University of Cape Town, 2013. v. 1. p. 213-222.

BARDIN, L. Análise de conteúdo. São Paulo: Edições 70, 2011.

BARDIN, L. Análise de conteúdo. Lisboa: Edições 70, 2009.

BERNSTEIN, B. Class, codes and control, volume IV: the structuring of pedagogic discourse. London: Routledge, 1990. $235 \mathrm{p}$.

BERNSTEIN, B. Pedagogy, symbolic control and identify: theory, research, critique. Lanham: Rowman \& Littlefield, 2000. $230 \mathrm{p}$. 
BEYER, H.O. A educação inclusiva: incompletudes escolares e perspectivas de ação. Revista Educação Especial, Santa Maria, v.1, n.1, 2012.

CANDAU, V.M. Pluralismo cultural, cotidiano escolar e formação de professores. In: CANDAU, V.M. (Org.). Magistério: construção cotidiana. Petrópolis: Vozes, 1998.

CARVALHO, R.E. Educação inclusiva e a criação de vínculos: um novo olhar. Revista Apae Ciência, v. 1, p. 19-32, 2014.

CERTEAU, M. A invenção do cotidiano-artes de fazer. 5. ed. Petrópolis: Vozes, 1994.

CORAZZA, S.M. Labirintos da pesquisa, diante dos ferrolhos. In: COSTA, Marisa V. (Org.) Caminhos investigativos: novos olhares na pesquisa em educação. Porto Alegre: Mediação, 1996, p. 1-22.

CRESWELL, J.W. Projeto de pesquisa: métodos qualitativos, quantitativos e misto. 3. ed. Porto Alegre: Artmed, 2007.

DEL PINO, M.A.B.; PORTO, G.C.A exclusão escolar na rede pública municipal de ensino: a história continua no século XXI. In: REUNIÃO ANUAL DA ANPED, 33, 2010, Caxambu/MG. Anais [...]. Caxambu, MG: ANPED, 2010.

ENZWEILER, D.A.; FRÖHLICH, R. Discursos sobre inclusão escolar no ciclo de alfabetização: uma análise sobre o pacto nacional pela alfabetização na idade certa (PNAIC). In: REUNIÃO ANUAL DA ANPED, 38, 2017, São Luís/MA. Anais [...]. São Luís, MA: ANPED, 2017.

FERREIRA, J. R. 0 GT educação especial: análise da trajetória da produção apresentada: 1991- 2000. 25ª Reunião Anual da Anped, Caxambu, 2002. Disponível em: http://www.anped.org.br/reunioes/25//te25.htm. Acesso em: 22 jun. 2020.

FERREIRA, N. S. A. As pesquisas denominadas "estado da arte". Educação \& Sociedade, Campinas, v. 23, n. 79, p. 257-272, ago. 2002.

FONTES, R.S. Ensino colaborativo: uma proposta de educação inclusiva. Araraquara: Junqueira \& Marin, 2007.

FREIRE, Paulo. A educação é um ato político. Cadernos de Ciência, Brasília, n. 24, p. 21-22, 1991.

GARNICA, A. Filosofia da educação matemática: algumas ressignificações e uma proposta de pesquisa. In: BICUD0, M.A.V. Pesquisa em educação matemática: concepções e perspectiva. São Paulo: Ed. UNESP, 1999. p. 59-74.

GERHARDT, T.E.; SILVEIRA, D.T. Métodos de pesquisa. Porto Alegre: UFRGS, 2009.

GIL, A. C. Como elaborar projetos de pesquisa. 4. ed. São Paulo: Atlas, 2002.

GINZBURG, C. Mitos, emblemas, sinais: morfologia e história. São Paulo. Companhia das Letras, 1989.

INGLES, M. A. et al. Revisão sistemática acerca das políticas de educação inclusiva para a formação de professores.

Rev. Bras. Ed. Esp., Marília, v. 20, n. 3, p. 461-478, jul./set., 2014.

JARDILINO, J. R.; ROSSI, G.; SANTOS, G.T. Orientações metodológicas para elaboração de trabalhos acadêmicos. São Paulo: Gion, 2000. 
LAKATOS, E. M.; MARCONI, M. A. Técnicas de pesquisa: planejamento e execução de pesquisas, amostragens e técnicas de pesquisas, elaboração, análise e interpretação de dados São Paulo: Atlas, 1999.

LEMO, D.P.; PESSOA, C.A.S. Educação financeira e educação matemática crítica no ensino médio: reflexões a partir de pesquisas. Revista de Educação, Ciências e Matemática, v. 8, n. 2, maio/ago. 2018.

MARCONI, M.A.; LAKATOS, E.M. Fundamentos de metodologia científica. 6. ed., 7. reimpressão. São Paulo: Atlas, 2009.

MENDES, E.G. A radicalização do debate sobre inclusão escolar no Brasil. Revista Brasileira de Educação, Campinas, v. 11, n. 33, p. 387-405, set./dez. 2006.

MOROSINI, M. C.; FERNANDES, C. M. B. Estado do Conhecimento: conceitos, finalidades e interlocuções. Educação Por Escrito, v. 5, p. 154-164, 2014. Disponível em: https://bit.ly/2IMF2F1. Acesso em: 22 jun. 2020.

MOREIRA, A.F.B.; MACEDO, E.F. Currículos, práticas pedagógicas e identidades. In: MOREIRA, A.F.B.; MACEDO, E.F. (Orgs.) Currículos, práticas e identidades. Porto: Porto Editora, 2002. p. 11-33.

MORIN, E. Da necessidade de um pensamento complexo. La relación antropobio-cósmica. Gazeta de Antropología, Granada, n. 11, 1995.

PEIXOTO, J.L.B. Análise dos esquemas de surdos sinalizadores associados aos significados da divisão. 2015a. $266 f$. Tese (Doutorado em Difusão do Conhecimento) - Faculdade de Educação. Universidade Federal da Bahia. Salvador, 2015.

PÉREZ GOMEZ, A. 0 pensamento prático do professor: a formação do professor como profissional reflexivo. In: NÓVOA, A. (Coord.) Os professores e a sua formação. Lisboa: Publicações Dom Quixote, 1995, p. 93-114.

PINHEIR0, F.A. et al. Ensino de matemática para surdos: mapeamento de pesquisas sobre resolução de problemas. Educação Matemática Debate, Montes Claros, Brasil, v. 4, p. 1-23, 2020.

PIMENTEL, M. Prática pedagógica e diversidade. In: REUNIÃO ANUAL DA ANPED, 32, 2009, Caxambu/MG. Anais [...] Caxambu, MG: ANPED, 2009.

PRADO, A.S.; SILVA, L.A.; SANTANA, T.S. Uma análise bernsteiniana de tarefas de modelagem do caso 1. In: CONFERÊNCIA NACIONAL SOBRE MODELAGEM MATEMÁTICA, 8., 2013, Santa Maria/RS. Anais [...]. Santa Maria, RS: SBEM, 2013. p. 1-12. 1 CD-ROM.

ROMANOWSKI, J. P.; ENS, R. T. As pesquisas denominadas do tipo "estado da arte". Diálogo Educacional, Curitiba, v. 6, n. 19, p. 37-50, set. 2006.

SAMPAIO, C.S.A complexidade do processo ensino-aprendizagem e a possibilidade de uma prática pedagógica inclusiva na escola de ensino fundamental. In: REUNIÃO ANUAL DA ANPED, 30, 2007, Caxambu/MG. Anais [...]. Caxambu, MG: ANPED, 2007.

SAMPAIO, C.S.; COSTA, M.S. Na articulação prática/teoria/prática a construção cotidiana de ações pedagógicas inclusivas. In: REUNIÃO ANUAL DA ANPED, 28, 2005, Caxambu/MG. Anais [...]. Caxambu, MG: ANPED, 2005. 
SCHÖN, D. Formar professores como profissionais reflexivos. In: NÓVOA, A. (Coord.) Os professores e a sua formação. 2. ed. Lisboa: Publicações Dom Quixote, 1995, p. 1-8.

SCHITTLER, D.; MOREIRA, M.A. Laser de rubi: uma abordagem baseada em unidades de ensino potencialmente significativas (UEPS). Latin-American Journal of Physics Education, v. 8, n. 2, p. 263-273, 2014.

SMOLKA, A. L. B. A criança na fase inicial da escrita: a alfabetização como processo discursivo. Campinas, São Paulo: Cortez, 1998.

TARDIF, M. Saberes profissionais dos professores e conhecimentos universitários. Revista Brasileira de Educação, ANPED, São Paulo, n. 13, p.5-24, jan./abr. 2000.

THESING, M.L.C; COSTAS, F.A.T. Estado do conhecimento e educação especial: um olhar para as produções da ANPED (2010 A 2015). In: REUNIÃo ANUAL DA ANPED, 38, 2017, Maranhão. Anais [...] Maranhão: ANPED, 2017.

THIOLLENT, M. Metodologia da pesquisa-ação. São Paulo: Cortez, 1994.

TRIVIÑOS, A.N. Introdução à pesquisa em ciências sociais: a pesquisa qualitativa em educação. São Paulo: Atlas, 1987.

VIEIRA-MACHADO, L.M.C.; LOPES, M.C. Experiências docentes: é possível viver com o outro desde fora da inclusão. In: REUNIÃO ANUAL DA ANPED, 37, 2015, Florianópolis/SC. Anais [...]. Florianópolis, SC: ANPED, 2015.

VYGOTSKY, L.S. A formação social da mente: 0 desenvolvimento dos processos psicológicos superiores. Tradução de José Cipolla Neto, Luís Silveira Menna Afeche e Solange Castro Afeche. São Paulo: Martins Fontes, 2007.

VYGOTSKY, L.S. A formação social da mente: 0 desenvolvimento dos processos psicológicos superiores. 4. ed. São Paulo: Martins Fontes, 1991.

VYGOTSKY, L.S. Formação social da mente. 3. ed. São Paulo: Martins Fontes, 1989.

RECEBIDO EM: 20 mai. 2020

CONCLUÍDO EM: 22 ago. 2020 